\title{
An Exploratory Step Toward Measuring the "Meaning of Life" in Patients with Tinnitus and in Cochlear Implant Users
}

\author{
Richard Tyler $^{1}$ Ann Perreauf ${ }^{2}$ Anne-Mette Mohr ${ }^{3}$ Helena ji ${ }^{1}$ Patricia C. Mancini ${ }^{4}$ \\ ${ }^{1}$ Department of Otolaryngology-Head and Neck Surgery, \\ University of lowa, lowa City, IA \\ 2 Department of Communication Sciences and Disorders, \\ Augustana College, Rock Island, IL \\ 3 Psykologcentret NV, Copenhagen NV, Denmark \\ ${ }^{4}$ Department of Speech-Language Pathology and Audiology, \\ Universidade Federal de Minas Gerais, Belo Horizonte, Brazil \\ Address for correspondence Richard S. Tyler, Department of \\ Otolaryngology-Head and Neck Surgery, University of lowa, lowa City, \\ IA 52242 (e-mail: rich-tyler@uiowa.edu).
}

J Am Acad Audiol 2020;31:277-285.

\begin{abstract}
Background Many questionnaires attempt to quantify the "quality of life." However, we believe understanding the quality of life is complex, and many widely used questionnaires do not capture the broad range of factors that we believe are important. Many do not include questions about communicating.

Purpose We developed a preliminary questionnaire designed to measure "The Meaning of Life" from a broader perspective.

Research Design We reviewed other scales and sought input from individuals with disabilities and developed an initial 23-item questionnaire.

Study Sample As a first step, we sampled 116 adults with tinnitus and 196 with cochlear implants (Cls). Individuals who were participating in our $\mathrm{Cl}$ or tinnitus research programs participated.

Data Collection and Analysis To compare differences between the two participant groups, independent sample f-tests were completed for specific items on the questionnaire and for the total score. We compared age and gender differences across all participants using f-tests. Statistical significance was defined as $p<0.05$. An exploratory factor analysis was conducted to examine the relationship among the questionnaire items using oblique rotation to produce correlated factors. Extracted factors with an eigenvalue $>1.0$ were retained according to the Kaiser-Guttman rule.

Results Four factors were prominent in this initial sample, which we labeled (1) friendship and positive outlook, (2) physical health, (3) hearing and mental health, and (4) satisfaction with life. Participants with tinnitus reported more trouble sleeping than participants with $\mathrm{Cl}$, whereas both groups had lower scores on hearing. Older patients

Keywords

- cochlear implants

- hearing loss

- quality of life

- questionnaires

- tinnitus reported more difficulty with remembering things but were more satisfied with their financial situation. Female participants reportedly had more hobbies and were more satisfied with their sex lives than male participants.

Conclusions This exploratory study intended to take a broader look at quality of life scales. Further work is needed with a larger sample including younger and older participants with and without disabilities.
\end{abstract}

Copyright $\odot 2020$ by the American Academy of Audiology. All rights reserved. Thieme Medical Publishers, Inc., 333 Seventh Avenue, New York, NY 10001, USA. Tel: +1(212) 760-0888.
DOI https://doi.org/ 10.3766/jaaa.19022. ISSN 1050-0545. 


\section{Introduction}

Quality of life scales are developed to measure individuals' feelings of their own health and well-being. The first scale was developed by the American psychologist John Flanagan and has been adapted for use in chronic illness groups (Flanagan, 1978; ${ }^{10}$ Burckhardt and Anderson, $2003^{3}$ ). There are currently several scales intended to measure functional ability, health status, psychological well-being, social networks and social support, and life satisfaction and morale (EuroQol Group, 1990; ${ }^{27}$ Ware and Sherbourne, $1992 ;{ }^{33}$ Brazier et al, 2002 ${ }^{2}$ ). For example, the Medical Outcomes Study 36-Item Short-Form Health Survey (SF-36) was designed for use in clinical practice and research, health policy evaluations, and general population surveys (Ware and Sherbourne, $1992^{33}$ ). This widely used questionnaire relies on patient self-reporting on eight dimensions of health: vitality, physical functioning, bodily pain, general health perceptions, physical role functioning, emotional role functioning, social role functioning, and mental health (using a magnitude estimation interval scale from 0 to 100 ). The SF-36 can be applied to over 200 diseases and has been translated into many languages (Garrat et al, 2002 ${ }^{11}$ ).

Derived from a selection of SF-36 items, the SF-6D is a classification for describing health (Brazier et al, 2002 ${ }^{2}$ ). It is composed of six multilevel dimensions and describes 18,000 health states in all. The SF-6D provides a means for using the SF-36 in economic evaluation by estimating a preferencebased single index measure for cost-effectiveness of health intervention analyses. Another widely used scale is the EQ$5 \mathrm{D}$, a standardized instrument developed in the United Kingdom that is based on items from the SF-36 and measures health-related quality of life (EuroQol Group, $1990^{27}$ ). This scale assesses how people perform on five dimensions of health: mobility, self-care, usual activities, pain/discomfort, and anxiety/depression (Brazier et al, 2002 2 ).

In practical terms, what exactly does "quality of life" mean? How happy are you? Can you take care of yourself or not? Do you have disabilities? Is it straightforward to compare one person's quality of life to another? Are we not all different; do we not have different needs and expectations? Does the public know what it is like to be deaf, or unable to talk, or see clearly? How do those without blindness or deafness know what it is like to be hard of vision or hearing? Would not your expectations and interpretation of your quality of life be influenced if you were retired or not, if you lived alone or not?

Health-related quality of life scales are very important as they are used to determine the effectiveness of a treatment and to compare treatments. In addition, in some countries, governments appropriate financial resources for different health-care problems depending on the relative benefit of treating different diseases.

Therefore, research focused on health-related quality of life is exceedingly important because of the implications one's quality of life can have on the effectiveness of current and future treatments, and on health care in a more general sense. In the development of quality of life scales, these measures are intended to reflect real-life experiences and challenges faced by everyone.
Typically, questionnaires are determined to be valid if (a) they measure what they state they are measuring, (b) they are reliable, and (c) they are sensitive (Kuk et al, $1990^{16}$; Edwards, $2010^{7}$ ). When a new questionnaire is developed, it is typically correlated to a previously published "gold standard" questionnaire to establish its validity.

Interestingly, many of the widely used scales contain no questions about hearing. Several have been applied to patients with hearing loss (Morgan et al, 2002;22 Stark and Hickson, $2004 ;{ }^{26}$ Barton et al, 2005; ${ }^{1}$ Chia et al, $2007 ;{ }^{4}$ Gopinath et al, $2012^{12}$ ) and cochlear implants (CIs) (Hinderink et al, 2000; ${ }^{14}$ Contrera et al, $2016^{5}$ ). Concerns from previous studies have evolved from these quality of life scales (e.g., EQ-5D and SF-6D) being unlikely to detect the expected quality of life deficits associated with hearing impairment (Morgan et al, 2002; 22 Barton et al, $2005^{1}$ ), for example. Therefore, some quality of life questionnaires have been developed to include questions on hearing. For example, the Health Utilities Index Mark 3 (Feeny et $\mathrm{al}, 1995^{8}$ ) is part of a health status classification system that evaluates health on eight attributes: vision, hearing, speech, ambulation, dexterity, emotion, cognition, and pain. The World Health Organization Disability Assessment Schedule 2.0 (WHO, 2010 35 ) is a generic assessment instrument for health and disability that covers six domains of functioning: cognition, mobility, self-care, getting along, life activities, and participation. Under the cognition domain, understanding and communication are evaluated, but we note that there is only one question assessing the "general understanding of what people say" on this instrument.

Our background in audiology has led us to focus on hearingrelated issues. The changes in quality of life and satisfaction after cochlear implantation have been documented before the generic health-related quality of life scales were developed (Wexler et al, 1982; ${ }^{34}$ Tyler and Kelsay, 1990; ${ }^{32}$ Maillet et al, $\left.1995^{18}\right)$. Hinderink et al $\left(2000^{14}\right)$ developed a handicap scale, the Nijmegen Cochlear Implantation Questionnaire, to determine quality of life changes for CI users. Three principal domains were distinguished: physical, psychological, and social (see also McRackan et al, 2017 ${ }^{21}$ ). Indeed, the National Institute on Deafness and Other Communication Disorders 2017-2021 Strategic Plan (NIH, 2008 ${ }^{23}$ ) states that there is a need for a universally accepted quality of life measure, specifically for use with $\mathrm{CI}$ patients, as research in quality of life has yet to produce a valid questionnaire.

This report raised our interest regarding what constitutes a valid quality of life measure. Quality of life is a broad concept that is affected by many events and circumstances. Quality of life was defined by the WHOQOL Group $\left(1995^{28}\right)$ as:

Individuals' perception of their position in life in the context of the culture and value systems in which they live and in relation to their goals, expectations, standards and concerns. It is a broad ranging concept affected in a complex way by the persons' physical health, psychological state, level of independence, social relationships and their relationship to salient features of their environment.

This definition led us to believe that a quality of life questionnaire must address a greater variety of real-life issues. It is important to consider that our needs in life change 
depending on our circumstances, that is, as we get older, if we do or do not have a job, or if we have or do not have a caregiver. Indeed, we are all different with different life experiences. Our perception of the quality of our life might depend on our age, our expectations, our gender, our employment status, and our personal interests, to name just a few examples.

In this article, as an initial step, we have attempted to address a broader range of activities related to everyday life, for all ages. We appreciate that this is not the final product but wanted to share our concerns about present scales and welcome input from others. Again, with our audiology background, we wanted to ensure the everyday difficulties associated with hearing loss are considered.

\section{Methods}

To determine the items for inclusion in the questionnaire, we discussed the meaning of "qualify of life" with research and clinical professionals (audiologists, physicians, and psychologists) involved in health care, and people who have a variety of handicaps (hearing, vision, and mobility). We asked them what areas they felt were important in their lives, and what questions would be relevant to capture things they felt were important in enjoying life, and what questions would best reflect the handicaps experienced by people with disabilities. As a first step, we explored these questions with individuals who were participating in our $\mathrm{CI}$ or tinnitus research programs at the University of Iowa. The preliminary questionnaire contained 23 items (see - Table 1).

The sample consisted of 312 adults, 116 of whom had tinnitus and 196 of whom had Cls. Of the 312 participants, 149 were females (mean age $=64.9$ years) and 163 were males (mean age $=65.8$ years). Participants' ages ranged from 23 to 88 years (average age $=65.4$ years); 231 were $>60$ years and 81 were 60 years old or younger. The mean age for the tinnitus group was 67.6 years (standard deviation $=5.6$ ) and for the $\mathrm{CI}$ group, the mean age was 64.1 years (standard deviation $=13.5$ ).

Some items address specific abilities related to physical health, whereas other items relate to emotional well-being, social interactions, and thoughts and emotions. Mean scores were calculated for each item, and an average total score was calculated from the average across the 23 items. To compare differences between the two participant groups using CIs and tinnitus, independent sample $t$-tests were completed for specific items on the questionnaire and for the total score. Also, we compared age and gender differences across all participants using $t$-tests. Data were analyzed using the Statistical Package for the Social Sciences (IBM SPSS Statistics for Windows, Version 24.0; IBM Corp., Armonk, NY) and Microsoft® Office Excel ${ }^{\circledR} 2007$ (Microsoft Press, Redmond, WA). For all tests, statistical significance was defined as $p<0.05$. Finally, an exploratory factor analysis was conducted to examine the relationship among the questionnaire items using oblique rotation to produce correlated factors. Extracted factors with an eigenvalue $>1.0$ were retained according to the KaiserGuttman rule; however, we first calculated the confidence interval for eigenvalues and confirmed that the entire confidence interval for these eigenvalues was $>1.0$.
Table 1 Meaning of Life Questionnaire. Participants Were Asked to "Please Indicate Your Agreement with Each Statement on a Scale from 0 (Completely Disagree) to 100 (Completely Agree)"

\begin{tabular}{|l|l|}
\hline Item & Statement \\
\hline 1. & I hear well in any situation. \\
\hline 2. & I see well in any situation. \\
\hline 3. & I walk easily in any situation. \\
\hline 4. & I talk well and am easily understood. \\
\hline 5. & I sleep well. \\
\hline 6. & I manipulate things well with my hands. \\
\hline 7. & I concentrate and focus well. \\
\hline 8. & I eat and drink with ease. \\
\hline 9. & I have many friends that I socialize with. \\
\hline 10. & I always remember things. \\
\hline 11. & I have many hobbies. \\
\hline 12. & I have emotional support from many others. \\
\hline 13. & I participate in several recreational activities. \\
\hline 14. & In general, I feel very relaxed. \\
\hline 15. & I am satisfied with my sex life. \\
\hline 16. & I am satisfied with my financial situation. \\
\hline 17. & I feel good about my self-image. \\
\hline 18. & I am very healthy. \\
\hline 19. & I have close friends or family that I can confide in. \\
\hline 20. & In general, I get all the pleasure I want out of life. \\
\hline 21. & I think the future looks very bright. \\
\hline 22. & I never feel depressed, sad, or anxious. \\
\hline 23. & I never experience pain or discomfort. \\
\hline
\end{tabular}

\section{Results}

Ratings for each of the 23 items and the total score for the two groups are presented in - Figure 1. The total score revealed an overall mean of $76.8 \%$ (standard error $=1.16$ ) for the participants with $\mathrm{CI}$ and $76.9 \%$ (standard error $=1.39$ ) for the participants with tinnitus. Item 8 ("I eat and drink with ease") received the highest ratings from both groups (94\% for participants with $\mathrm{Cl}$ and $95 \%$ for participants with tinnitus), followed by items 6 ("I manipulate things well with my hands") and 19 ("I have close friends or family that I can confide in"). The lowest mean rating ( $48 \%$ for both groups) was found on item 1 ("I hear well in any situation"). Items 22 ("I never feel depressed, sad, or anxious") and 23 ("I never experience pain or discomfort") also had a low mean score of z60\% for participants with CI and tinnitus. In addition, item 5 ("I sleep well") produced the greatest difference in scores between participants with $\mathrm{CI}$ and tinnitus, with lower scores for the tinnitus group. Independent sample $t$-tests were performed to determine significant differences between participants with $\mathrm{CI}$ and tinnitus across the 23 items. Ratings were significantly different $(p<0.05)$ in items 5 ("I sleep well"), 10 ("I always remember things"), 12 ("I have emotional support from many others"), 17 ("I feel good 


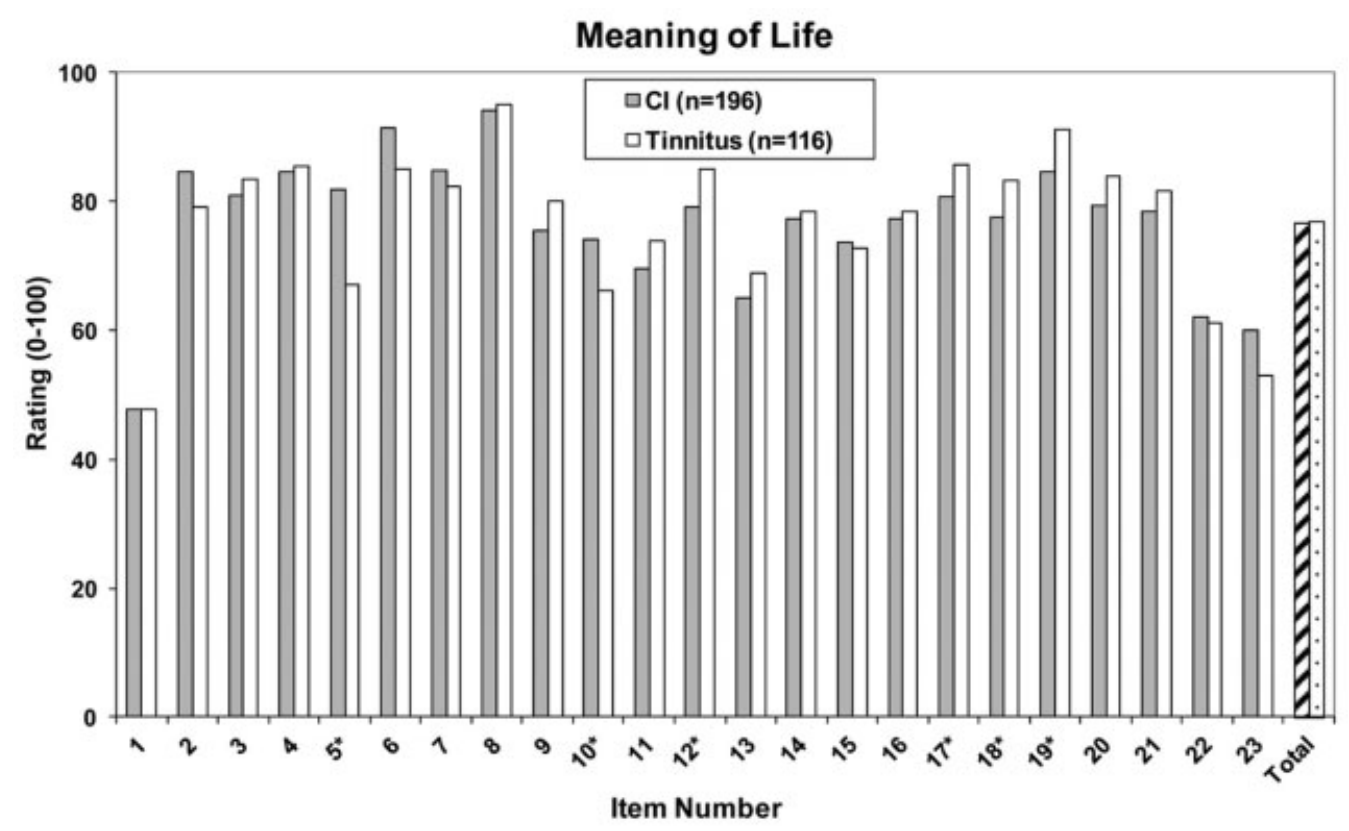

Fig. 1 Mean ratings (in a scale of $0-100 \% ; 0=$ completely disagree and $100=$ completely agree) for participants with $\mathrm{Cl}(\mathrm{n}=196)$ and participants with tinnitus $(n=116)$ for all 23 items, and total score.

about my self-image"), 18 ("I am very healthy"), and 19 ("I have close friends or family that I can confide in").

- Figure 2 shows the ratings grouped by age. Total scores averaged $76.3 \%$ for participants aged $>60$ years $(\mathrm{N}=231)$ and $78.2 \%$ for those aged 60 years or younger $(N=81)$. The highest mean ratings for all ages were observed on items 8 ("I eat and drink with ease") and 6 ("I manipulate things well with my hands"), and the lowest ratings were identified on items 1 ("I hear well in any situation") and 23 ("I never experience pain or discomfort"). We note that the greatest difference on the mean ratings between groups was observed for item 1 ("I hear well in any situation"); the mean rating of participants aged $>60$ years was $44 \%$, whereas $57 \%$ was found for those aged \#60 years. Independent sample $t$-tests were performed to determine significant differences between young and old participants on the 23 items. Ratings were significantly different $(p<0.05)$ on item 1 ("I hear well in any situation."), 4 ("I talk well and am easily understood"), 6 ("I manipulate things well with my hands"), 7 ("I concentrate and focus well"), 8 ("I eat and drink with ease"), 10 ("I always remember things"), 11 ("I have many hobbies"), and 16 ("I am satisfied with my financial situation").

We also compared the ratings across male $(\mathrm{N}=163)$ and female $(\mathrm{N}=149)$ participants, combining $\mathrm{CI}$ and tinnitus

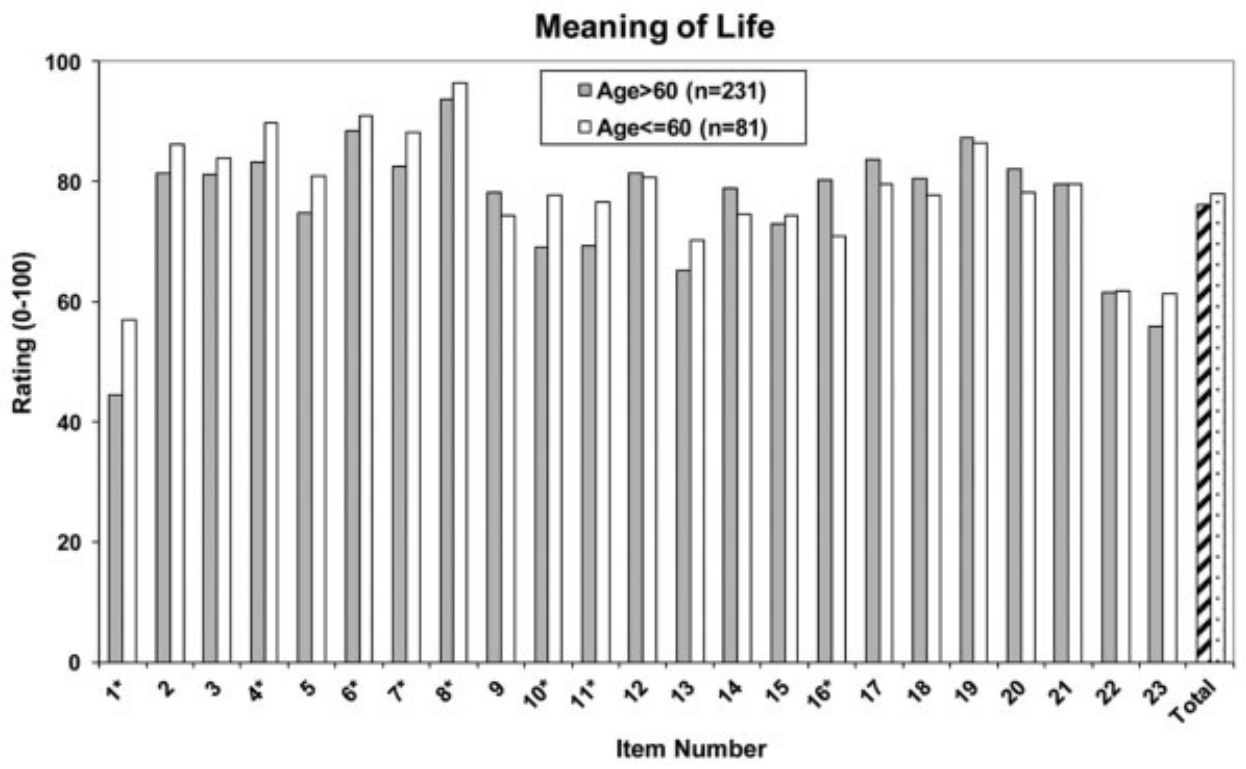

Fig. 2 Mean ratings grouped by age (age $>60=5$ gray bars; age $\leq 60$ years $=$ white bars). 


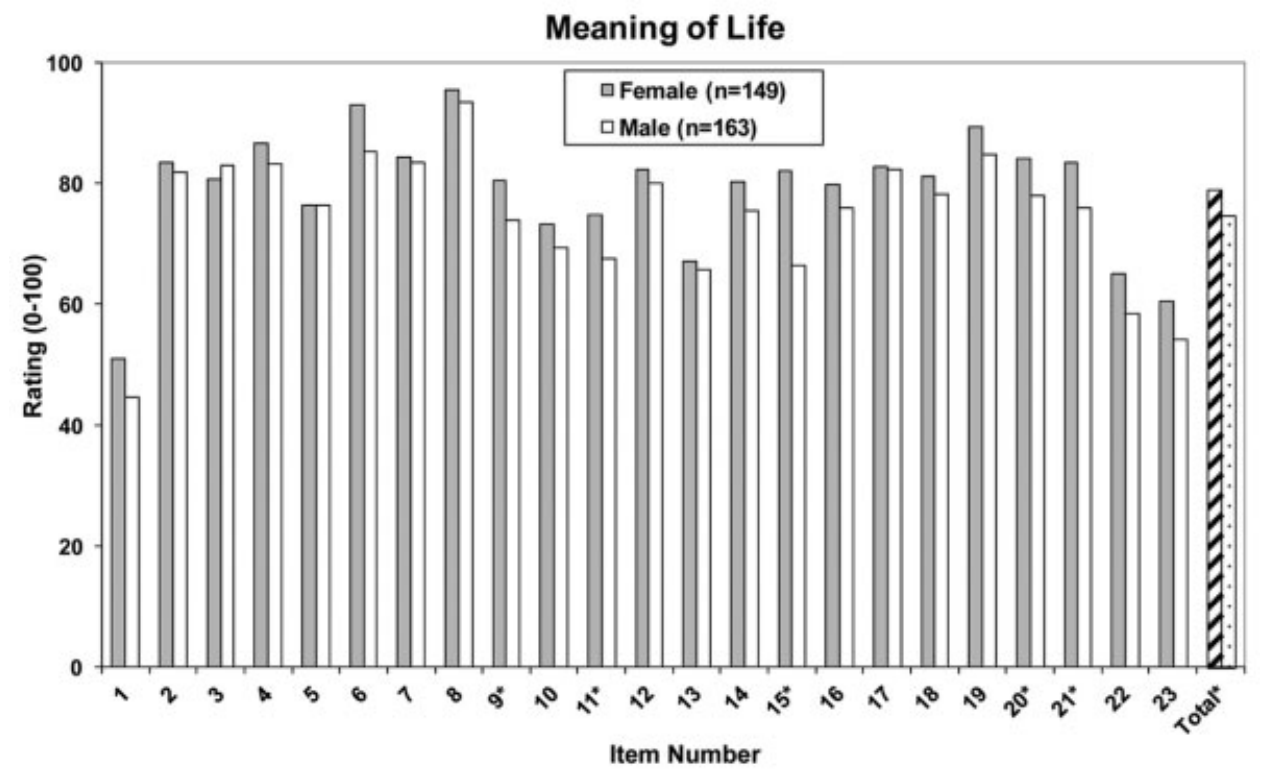

Fig. 3 Mean ratings of participants grouped by gender (female = gray bars; male = white bars).

participant groups. - Figure 3 shows the mean ratings for males and females across the 23 items and for the total score. In general, females exhibited higher mean ratings than males for all items. The total scores averaged $74.8 \%$ for males and $79.0 \%$ for females. The highest mean rating for both genders was observed for item 8 ("I eat and drink with ease"), in which the mean rating for males was $93.5 \%$ and for females was $95.6 \%$. The lowest ratings were identified for items 1 (44.7\%; "I hear well in any situation") and 23 (54.3; "I never experience pain or discomfort"). Independent sample $t$-tests were performed to determine if these differences between male and female participants were statistically significant. Differences were highly significant $(p<0.05)$ for items 9 ("I have many friends that I socialize with"), 11 ("I have many hobbies"), 15 ("I am satisfied with my sex life"), 20 ("In general, I get all the pleasure I want out of life"), and 21 ("I think the future looks very bright"), and for the total score.

Individual ratings for the total score were plotted against age, as shown in - Figure 4. In general, lower mean ratings were found for participants aged between 55 and 75 years and higher mean ratings were reported for participants aged between 60 and 80 years.

\section{Factor Analysis}

A factor analysis was used to examine the shared features among items of the Meaning of Life Questionnaire. Initially, to determine whether factor analysis was adequate for the data, the Kaiser-Meyer-Olkin (KMO; SPSS v. 24.0) measure of sampling adequacy was computed. The KMO determines the proportion of variance among variables that might be

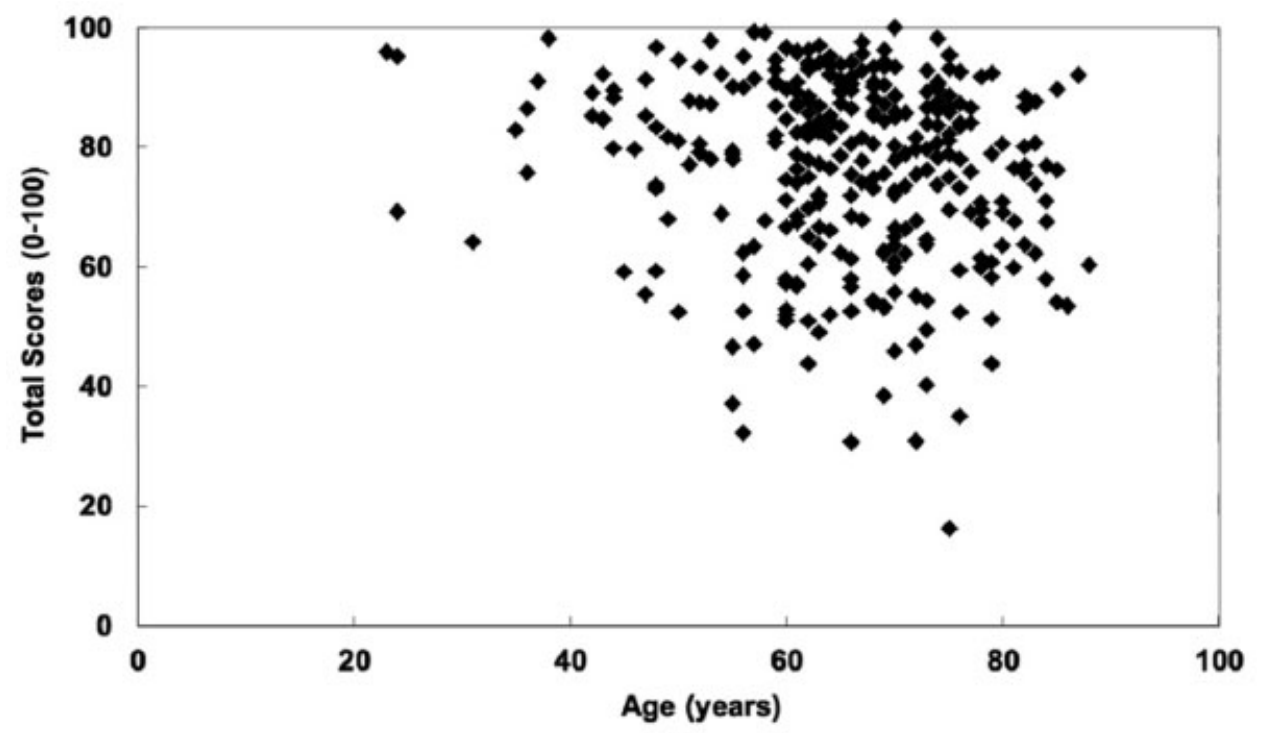

Fig. 4 Age of participants (x-axis) and individual mean ratings of total score in the Meaning of Life Questionnaire (y-axis). 
common variance. Factor analysis is deemed appropriate when the KMO ratio among the observed variables is close to 1 . A ratio of 0.91 was found for the set of 23 items, indicating that factor analysis was appropriate to explore the underlying factors of the questionnaire.

To further evaluate the structure of the questionnaire, an exploratory factor analysis with oblique rotation assuming correlated factors was conducted. The factor analysis revealed four factors with eigenvalues (and confidence intervals) greater than one. The first factor explained $42.3 \%$ of the total variance (eigenvalue $=9.7$ ); the second factor explained $7.4 \%$ of the total variance (eigenvalue $=1.7$ ); the third factor explained $6.7 \%$ of the total variance (eigenvalue $=1.5$ ); and the fourth factor explained $4.6 \%$ of the total variance (eigenvalue $=1.1$ ). This suggests that the 23 original items can be reduced to four underlying factors. The four factors explained $61 \%$ of the total variance in the responses from all 312 participants with $\mathrm{CI}$ and tinnitus.

The structure matrix contains estimates of the correlations between each of the variables and the estimated factors. To determine the shared features among the items, the proportion of variance in each item (or communality values) was first examined. Values $>0.50$ indicate high correlations between the items and the factors. The communality values of each variable explained by these four factors ranged from 0.55 to 0.86 (see - Table 2).

Analyzing the four separate factors, seven items loaded on factor 1, nine items loaded on factor 2, 5 items loaded on factor 3 , and two items loaded on factor 4 . Further examination of these factors revealed that items from factor $1(9,11,12,13,19$, 20 , and 21) relate to friendship with others and positive outlook on one's life. For factor 2 , items $2,3,4,6,7,8,10,17$, and 18 relate to one's physical health. For factor 3, items 1, 5,14, 22, and 23 relate to one's hearing and mental health. For factor 4, items 15 and 16 relate to the degree of satisfaction in one's life.

After examining the statements within each factor, we propose the following labels: (a) friendship and positive outlook, (b) physical health, (c) hearing and mental health, and (d) satisfaction.

\section{Discussion}

The purpose of this investigation was to explore the "quality of life" with a broader set of questions relevant to day-to-day activities. We considered this as a first step. With our interest in audiology, we want to ensure that the broad consequences of hearing loss are represented and that these items were sensitive to changes in hearing function. The comparison

Table 2 Communality Values and Factor Loadings for the Meaning of Life Questionnaire

\begin{tabular}{|c|c|c|c|c|c|c|}
\hline \multirow[t]{2}{*}{ Factor } & \multirow[t]{2}{*}{ Item } & \multirow[t]{2}{*}{ Statement } & \multicolumn{4}{|c|}{ Factor Matrix } \\
\hline & & & 1 & 2 & 3 & 4 \\
\hline \multirow[t]{7}{*}{1 (friendship and positive outlook) } & 9 & I have many friends that I socialize with. & 0.774 & & & \\
\hline & 11 & I have many hobbies. & 0.652 & & & \\
\hline & 12 & I have emotional support from many others. & 0.838 & & & \\
\hline & 13 & I participate in several recreational activities. & 0.630 & & & \\
\hline & 19 & I have close friends or family that I can confide in. & 0.855 & & & \\
\hline & 20 & In general, I get all the pleasure I want out of life. & 0.721 & & & \\
\hline & 21 & I think the future looks very bright. & 0.688 & & & \\
\hline \multirow[t]{9}{*}{2 (physical health) } & 2 & I see well in any situation. & & 0.764 & & \\
\hline & 3 & I walk easily in any situation. & & 0.754 & & \\
\hline & 4 & I talk well and am easily understood. & & 0.604 & & \\
\hline & 6 & I manipulate things well with my hands. & & 0.714 & & \\
\hline & 7 & I concentrate and focus well. & & 0.695 & & \\
\hline & 8 & I eat and drink with ease. & & 0.662 & & \\
\hline & 10 & I always remember things. & & 0.656 & & \\
\hline & 17 & I feel good about my self-image. & & 0.583 & & \\
\hline & 18 & I am very healthy. & & 0.603 & & \\
\hline \multirow[t]{5}{*}{3 (hearing and mental health) } & 1 & I hear well in any situation. & & & 0.547 & \\
\hline & 5 & I sleep well. & & & 0.712 & \\
\hline & 14 & In general, I feel very relaxed. & & & 0.718 & \\
\hline & 22 & I never feel depressed, sad, or anxious. & & & 0.839 & \\
\hline & 23 & I never experience pain or discomfort. & & & 0.765 & \\
\hline \multirow[t]{2}{*}{4 (satisfaction) } & 15 & I am satisfied with my sex life. & & & & 0.783 \\
\hline & 16 & I am satisfied with my financial situation. & & & & 0.693 \\
\hline
\end{tabular}


between $\mathrm{Cl}$ users and participants with tinnitus showed lowest mean ratings for both groups on item 1 ("I hear well in any situation"). Because all participants presented hearing disorders, hearing may be considered an important aspect of the meaning of life for this sample. As reported by many researchers, CIs result in a very perceptible improvement in communication and also in patients' perception of their quality of life (Tyler and Kelsay, 1990; ${ }^{32}$ Maillet et al, $1995 ;{ }^{18}$ Lin et al, 2012; ${ }^{17}$ Contrera et al, 2016 ${ }^{5}$ ). However, even after patients receive a $\mathrm{Cl}$, they often continue to report difficulties in everyday activities, such as hearing in the presence of background noise, listening to music, and using the telephone (Tyler and Kelsay, $1990 ;{ }^{32}$ Maillet et al, 1995; ${ }^{18}$ Pisoni, 2000; ${ }^{24}$ Firszt et al, $2004^{9}$ ). Lower ratings were also observed on items 22 ("I never feel depressed, sad, or anxious") and 23 ("I never experience pain or discomfort"). We know that hearing loss can contribute to social isolation, loneliness, frustration, and dependence on a caregiver. However, after patients receive a $\mathrm{CI}$, they often report an improvement in these aspects that contribute to one's quality of life (Tyler and Kelsay, $1990 ;^{32}$ Maillet et al, $\left.1995^{18}\right)$. Maillet et al $\left(1995^{18}\right)$ evaluated the changes in the quality of life of $\mathrm{CI}$ users between preimplantation and 24 months postimplantation. They also examined the relationship between age, years of deafness, and speech recognition ability, and their satisfaction in life. The results showed that after cochlear implantation, patients had a significant and positive change in the quality of life and in their ability to communicate. In addition, the degree of perceived improvement in the quality of life was a function of the years that the patients had been deaf: patients who were deaf for \#10 years had significantly greater improvement after receiving the $\mathrm{CI}$ than those who were deaf for $\$ 20$ years (Maillet et al, $1995^{18}$ ).

Here, participants with tinnitus were found to be more severely affected by sleeping problems than participants with $\mathrm{CI}$. This result was expected because sleep disturbance has long been recognized as the single most important complaint among adults with tinnitus (Tyler and Baker, 1983; ${ }^{29}$ McKenna, 2000; ${ }^{19}$ McKenna and Daniel, 2006 ${ }^{20}$ ). On the item "I hear well in any situation," participants with tinnitus scored higher than CI recipients. Tyler and Kelsay $\left(1990^{32}\right)$ explored the disadvantages of cochlear implantation for 53 of some of the better CI patients. In this study, the main disadvantages were found to be environmental sound perception (reported by $47 \%$ of the sample), and speech perception when speechreading may be used (17\%). Therefore, many $\mathrm{CI}$ patients have difficulty with speech perception, especially in noisy environments. Tyler and Baker (1983;29 see also Henry et al, $2015^{13}$ ) reported that it is difficult for some patients with tinnitus to distinguish hearing difficulties caused by hearing loss from difficulties caused by tinnitus. This is an issue that must be addressed in individual counseling for patients with tinnitus, as recommended by Tinnitus Activities Treatment (Tyler et al, 2006; $2007^{31}$ ). Providing a general understanding to patients with tinnitus on hearing, hearing loss, and tinnitus can help in many ways: (a) it helps patients realize they are not alone in having tinnitus, (b) it removes misconceptions and some of the fear patients may have of the unknown, and (c) it assists patients in being able to develop realistic expectations with regard to what is likely to change during tinnitus treatment (Tyler et al, $2006 ;^{30} 2007^{31}$ ).

We noted that age had an influence on the ratings given by participants, especially for items 10 ("I always remember things") and 16 ("I am satisfied with my financial situation"). Participants who were aged $>60$ years had lower ratings for item 10 on memory, in agreement with the common knowledge on the association between age and memory loss. Certain brain changes are observed with age, and z50\% of people in the community aged $>50$ years report complaints of forgetfulness (Koivisto et al, $1995^{15}$ ). On the other hand, higher scores were reported by the older age group for the latter statement ("I am satisfied with my financial situation"). One reason may rely on the fact that young people are grappling with choosing and establishing careers, finding life partners, handling the emotional stress of building a stable life, and navigating financial issues, whereas older individuals have progressed through these changes in the later years of their life.

The questionnaire showed also that men and women are different regarding their feelings of satisfaction and happiness. Females presented with higher ratings in all statements, and significant differences were observed on items from factors labeled friendship and positive outlook, and satisfaction. A number of studies have suggested that women may be more empathetic than men, and a model for gender differences in empathy has been proposed (Decety and Jackson, 2004; ${ }^{6}$ Rueckert and Naybar, 2008 ${ }^{25}$ ). Therefore, our study showed the contingent nature of the perception of quality of life by gender.

Questionnaires of quality of life should provide information about the impact of a disability and its treatment. We were concerned that many of the present widely used scales are not sufficiently broad, and many do not include or are sensitive to the consequences of hearing loss. We consider this only the first step and welcome comments to enhance this questionnaire. In future studies, we aim to administer the questionnaire to individuals with vision and mobility challenges. We also think it is important to consider other aspects of diversity, such as ethnicity, socioeconomic status, employment status, and interest in hobbies, which are likely to influence the questionnaire responses. For example, hearing ability is particularly important for musicians. Because musicians depend on good hearing to perform and practice, it should be reasonable to assume that hearing is an important part of musicians' definition of their "quality of life." If a musician has hearing loss, would this not have a greater impact on his or her quality of life than on others who are not musicians? In this way, we maintain that hearing is likely to affect one's quality of life and quality of life assessments that are sensitive to changes in hearing function and communication abilities should be implemented in research and clinical practice.

Finally, there are some shortcomings to our study. It is likely that some $\mathrm{CI}$ respondents also had tinnitus. 
Therefore, there is no definitive distinction between the $\mathrm{CI}$ and the tinnitus groups. In a future study, we will explore differences between $\mathrm{CI}$ recipients with and without tinnitus. Overall, our research indicated that hearing ability deeply impacts the quality of life of individuals with hearing disorders. Also, differences in specific areas of quality of life were observed in the responses given by the participants when grouped by those with CIs and tinnitus, and older and younger adults. These differences demonstrate that the meaning of "quality of life" is an individual concept which depends on many circumstances. The contingent nature of quality of life evaluation makes it difficult to construct one scale that is suitable for a diverse range of people. Perhaps it is necessary to adjust the quality of life based on age, gender, and vocation.

Our purpose was to create an opportunity to investigate quality of life in a different manner and to provide a starting point to proceed in a different direction than previously done. We also hope to raise some cautionary note for all who investigate the quality of life. Indeed, we do believe that the complexity and diversity of this concept have not been fully appreciated.

\section{Abbreviations}

CI cochlear implants

KMO Kaiser-Meyer-Olkin

\section{Acknowledgments}

Conselho Nacional de Desenvolvimento Cientifico e Tecnologico (CNPq), Brazil, provided a scholarship to Dr. Mancini.

\section{References}

1 Barton GR, Bankart J, Davis AC. A comparison of the quality of life of hearing-impaired people as estimated by three different utility measures. Int J Audiol 2005 44:157-163

2 Brazier JB, Roberts J, Deverill M. The estimation of a preferencebased measure of health from the SF-36. J Health Econ 2002 21:271-292

3 Burckhardt CS, Anderson KL. The Quality of Life Scale (QOLS): reliability, validity, and utilization. Health Qual Life Outcomes 2003 23(01):60-66

4 Chia EM, Wang JJ, Rochtchina E, Cumming RR, Newall P, Mitchell P. Hearing impairment and health-related quality of life: the Blue Mountains Hearing Study. Ear Hear 2007 28(02):187-195

5 Contrera KJ, Betz J, Li L, Blake CR, Sung YK, Choi JS, Lin FR. Quality of life after intervention with a cochlear implant or hearing aid. Laryngoscope 2016 126(09):2110-2115

6 Decety J, Jackson PL. The functional architecture of human empathy. Behav Cogn Neurosci Rev 2004 3:71-100

7 Edwards P. Questionnaires in clinical trials: guidelines for optimal design and administration. Trials 2010 11:2-9

8 Feeny D, Furlong W, Boyle M, Torrance GW. Multi-attribute health status classification systems. Health Utilities Index. PharmacoEconomics 1995 7(06):490-502

9 Firszt JB, Holden LK, Skinner MW, Tobey EA, Peterson A, Gaggl W, Runge-Samuelson CL, Wackym PA. Recognition of speech presented at soft to loud levels by adult cochlear implant recipients of three cochlear implant systems. Ear Hear 2004 25:375-387
10 Flanagan JC. A research approach to improving our quality of life. Am Psychol 1978 33:138-147

11 Garrat AM, Schmidt L, Mackintosh A, Fitzpatrick R. Quality of life measurement: bibliographic study of patient assessed health outcome measures. BMJ Open 2002 324:1417-1421

12 Gopinath B, Schneider J, Hickson L, McMahon CM, Burlutsky G, Leeder SR, Mitchell P. Hearing handicap, rather than measured hearing impairment, predicts poorer quality of life over 10 years in older adults. Maturitas 2012 72:146-151

13 Henry JA, Griest S, Zaugg TL, Thielman E, Kaelin C, Galvez G, Carlson KF. Tinnitus and hearing survey: a screening tool to differentiate bothersome tinnitus from hearing difficulties. Am JAudiol 2015 24(01):66-77

14 Hinderink JB, Krabbe PF, Van Den Broek P. Development and application of a health-related quality-of-life instrument for adults with cochlear implants: the Nijmegen cochlear implant questionnaire. Otolaryngol Head Neck Surg 2000 123(06):756-765

15 Koivisto K, Reinikainen KJ, Hanninen T, Vanhanen M, Helkala E, Mykkanen L, Laakso M, Pyorala K, Riekkinen PJ. Prevalence of aged-associated memory impairment in a randomly selected population from eastern Finland. Neurology 1995 45:741-747

16 Kuk FK, Tyler RS, Russell D, Jordan H. The psychometric properties of a tinnitus handicap questionnaire. Ear Hear 1990 11(06):434-442

17 Lin FR, Chien WW, Li L, Clarrett DM, Niparko JK, Francis HW. Cochlear implantation in older adults. Medicine 2012 91(05):229-241

18 Maillet CJ, Tyler RS, Jordan HN. Change in the quality of life of adult cochlear implant patients. Ann Otol Rhinol Laryngol Suppl 1995 165:31-48

19 McKenna L. Tinnitus and insomnia. In: Tyler RS, ed. Tinnitus Handbook. San Diego, CA: Singular Publishing Group; 2000 59-84

20 McKenna L, Daniel HC. Tinnitus-related insomnia treatment. In: Tyler RS, ed. Tinnitus Treatment: Clinical Protocols. New York, NY: Thieme; 2006:81-95

21 McRackan TR, Velozo CA, Holcomb MA, Camposeo EL, Hatch JL, Meyer TA, Lambert PR, Melvin CL, Dubno JR. Use of adult patient focus groups to develop the initial item bank for a cochlear implant quality-of-life instrument. JAMA Otolaryngol Head Neck Surg 2017 143(10):975-982

22 Morgan A, Hickson L, Worral L. The impact of hearing impairment on quality of life of older people. Asia Pacif J Speech Lang Hear 2002 7:39-53

$23 \mathrm{NIH}$. National Institute on Deafness and Other Communication Disorders (NIDCD) 2017-2021 Strategic Plan. Bethesda, MD: National Institute of Health; 2008https://www.nidcd.nih.gov/ about/strategicplan/2017-2021-nidcd-strategic-plan/. Accessed February 1, 2018

24 Pisoni DB. Cognitive factors and cochlear implants: some thoughts on perception, learning, and memory in speech perception. Ear Hear 2000 21:70-78

25 Rueckert L, Naybar N. Gender differences in empathy: the role of the right hemisphere. Brain Cogn 2008 67(02):162-167

26 Stark P, Hickson L. Outcomes of hearing aid fitting for older people with hearing impairment and their significant others. Int J Audiol 2004 43(07):390-398

27 The EuroQol Group. EuroQol-a new facility for the measurement of health-related quality of life. Health Policy 1990 36:199-208

28 The WHOQOL Group. The World Health Organization Quality of Life assessment (WHOQOL): position paper from the World Health Organization. Soc Sci Med 1995;41:1403

29 Tyler RS, Baker LJ. Difficulties experienced by tinnitus sufferers. J Speech Hear Disord 1983 48(02):150-154

30 Tyler RS, Gehringer AK, Noble W, Dunn CC, Witt SA, Bardia A. Tinnitus activities treatment. In: Tyler RS, ed. Tinnitus Treatment: Clinical Protocols. New York, NY: Thieme; 2006:116-132

31 Tyler RS, Gogel SA, Gehringer AK. Tinnitus activities treatment. Prog Brain Res 2007 166:425-434

32 Tyler RS, Kelsay D. Advantages and disadvantages reported by some of the better cochlear implant patients. Am J Otol 1990;11 (04):282-289 
33 Ware JE, Sherbourne CD. The MOS 36-item short health survey (SF-36) I. Conceptual framework and item selection. Med Care 1992 30:473-483

34 Wexler M, Miller LW, Berliner KI, Crary WG. Psychological effects of cochlear implant: patient and 'index relative' perceptions. Ann Otol Rhinol Laryngol 1982 91:59-61
35 WHO, Cataloguing-in-Publication Data. Ubstun TB, Kostanjsek N, Chatterji S, Rehm J eds.Measuring Health and Disability: Manual for World Health Organization Disability Assessment Schedule (WHODAS 2.0). 2010http://apps.who.int/iris/bitstream/handle/10665/ 43974/9789241547598_eng.pdfjsessionid=1B6A854A5D2F8165D 539DBBFB6106E64? sequence=1. Accessed February 4, 2018 